Association for Information Systems

AIS Electronic Library (AISeL)

\title{
Preparing for an Uncertain Future: South Westphalia City Scenarios 2030
}

Anja Schulte

Fachhochschule Südwestfalen

Tim Wittemund

Fachhochschule Südwestfalen

Peter Weber

Fachhochschule Südwestfalen

Alexander Fink

Scenario Management International ScMI AG

Follow this and additional works at: https://aisel.aisnet.org/wi2021

Schulte, Anja; Wittemund, Tim; Weber, Peter; and Fink, Alexander, "Preparing for an Uncertain Future: South Westphalia City Scenarios 2030" (2021). Wirtschaftsinformatik 2021 Proceedings. 3. https://aisel.aisnet.org/wi2021/SSmartCity/Track08/3

This material is brought to you by the Wirtschaftsinformatik at AIS Electronic Library (AISeL). It has been accepted for inclusion in Wirtschaftsinformatik 2021 Proceedings by an authorized administrator of AIS Electronic Library (AISeL). For more information, please contact elibrary@aisnet.org. 


\title{
Preparing for an Uncertain Future: South Westphalia City Scenarios 2030
}

\author{
Anja Schulte ${ }^{1}$, Tim Wittemund ${ }^{1}$, Peter Weber $^{1}$, Alexander Fink ${ }^{2}$ \\ ${ }^{1}$ Fachhochschule Südwestfalen, Soest, Germany \\ \{weber.peter,schulte.anja,wittemund.tim\}@fh-swf.de \\ 2 Scenario Management International ScMI AG, Paderborn, Germany \\ fink@scmi.de
}

\begin{abstract}
For example, because of the demographic change, the fast pace of technological advance, and changing citizen habits (e.g. in buying behavior), cities face fundamental challenges and lack orientation in approaching their (digital) transformation. Especially cities in rural areas struggle in this situation which makes it necessary to reconsider predominant structures in city management. The use of scenario management can support decision-making processes by broadening the perspective through thinking in future scenarios. This paper elaborates on a scenario planning project that was conducted with 25 cities from South Westphalia (Germany) in 2020. Eight scenarios have been developed in a multi-stakeholder process with participants from different city domains. Both, the process of scenario planning and the developed city scenarios for 2030, aim to support city managers and other city stakeholders expand their focus, triggering a future-oriented examination of cities.
\end{abstract}

Keywords: scenario management, action design research, city centers in rural areas, smart city

\section{Introduction}

Urbanization is a much cited challenge in smart city publications - too many citizens for the existing infrastructure. Despite an increase in city residents, the vitality of city centers seems to decline. This paradox deserves attention: on the one hand, an increasing number of people moves into the cities, prospectively $70 \%$ of the population until 2050, while on the other hand, a decreasing number of people visits the actual city centers [1]. As a consequence of declining city visitors, stationary retail is at stake [2]. The concept of a smart city suggests answers to the major city challenges by using modern information technologies to improve the planning of the cities and to reach sustainable economic growth and a high quality of life [3], [4]. It is a holistic concept that aims to implement improvements in six city-related areas (environment, living, people, economy, mobility and government), connecting the stakeholders in order to co-create accepted solutions [5]. Thereby, a citizen-centric focus shall ensure especially the acceptance by citizens, harnessing also new forms of political participation [6].

16th International Conference on Wirtschaftsinformatik, March 2021, Essen, Germany 
To help the cities tackle their challenges and maintain their vitality, the EU-funded project City Lab Südwestfalen aims to support proactive city transformation. In order to provide orientation and to create a more robust basis for strategic decisions, a scenario process was initiated, involving a broad range of city stakeholders.

Against the background of curfews and COVID-19 restrictions, the Association of German Cities and Towns warns against the death of city centers making the discussion of city transformation and smart city concepts even more relevant [7]. Despite respective funding programs of the federal government, the complexity of the topic and the uncertainty about future developments hampers planning in many cities. The predominant uncertainties demand for a methodological approach to support systematic decision-making. Scenario planning can help to reduce the complexity of an unknown future by building different scenarios that could occur in a defined timespan. Both, the process of scenario planning and the resulting scenarios, support city managers and other city stakeholders expand their focus, triggering a future-open examination of the cities.

\section{Problem and Research Questions}

In April 2019, the Federal Ministry of the Interior, Building and Community (German: $\mathrm{BMI}$ ) announced to fund the digital change of cities throughout the upcoming decade with 750 million euros [8]. The Ministry called for 50 smart city pilot projects aiming at the creation and maintenance of modern, technology-supported cities worth living. A proclaimed goal is the strategic implementation of digitalization by the cities. However, a study by the German Association of Towns and Municipalities (German: DStGB) reveals that only half of the 538 queried cities currently have a defined digitalization strategy [9]. Due to the multitude of tasks and the fast pace of technological change, cities lack orientation to answer the questions what is to do, and when, how and in which order to approach the challenge of digitalization. This leads to the threat of isolated, uncoordinated efforts and bad investments. In order to face this problem, this paper addresses the following research questions (RQs):

RQ1: How can a multi-city scenario planning process be accomplished to help the cities in South Westphalia prepare for an uncertain future?

RQ2: What are possible future scenarios of South Westphalian city centers in 2030?

These questions were examined as part of the EFRE-Project City Lab Südwestfalen, involving 25 (out of 59) cities in South Westphalia (North-Rhine Westphalia, Germany). While the scenario process itself can be transferred also to other regions and cities, it does not lead to turnkey solutions. Every city needs to assess and work with the scenarios individually, considering its own initial situation, development path, and objectives. 


\section{$3 \quad$ Theoretical Grounding}

\subsection{Scenario Development}

In order to work out profound concepts to apply for the offered funding programs and to align digitalization projects in a future-oriented way, cities need to deal with potential future developments systematically. Scenario planning as a method of future research presents a strategic instrument for this.

A scenario is "a description of a future situation and the development of the path that leads from the present to the future" [10]. Scenarios enable individuals, companies or other organizations to consider possible future developments in their decisions today. The scenario method is a planning technique to develop a set of heterogeneous but internally consistent scenarios [10].

Literature offers a variety of scenario methods. A comparison by Mietzner (2009) reviews five selected model-based methods (methods using algorithms) and three intuitive methods [11], helping us to choose the most appropriate approach. As part of the model-based approaches, von Reibnitz (1992) proposes a systematic and transparent eight-step process named scenario technique [10]. Anyhow, as in her approach the number of scenarios is originally limited to three (best-case, worst-case, trend), it can lead to a black-and-white manner of thinking. Addressing this issue, the scenario management approach by Fink/Siebe (2016) which is closely related to the scenario technique, aims at the development of four up to ten scenarios instead [12]. Burmeister et al. (2004) regard scenarios as one component of a complex toolbox for strategic foresight [13]. Since their method includes a more dedicated trend monitoring and offers less process definitions, it does not match with our intentions. While Godet et al.'s (2001) integrated "La Prospective" approach is focused on deriving strategic implications, it is criticized for being highly complex [11], [14]. The probability theories by Helmer/Gordon (1994) also do not match, considering the given uncertainty and complexity of the cities' future, as this prevents from assessing probabilities in a reliable manner [15]. Finally, we also decided against the intuitive approaches (Schwartz (1996), van der Heijden (2002), Schoemaker (2002), Ramirez/Wilkinson (2016), Cairns/Wright (2018)), as they lack detailed descriptions of the scenario development process while containing many elements similar to the model-based approaches [11], [16-20].

For a well-founded choice of the appropriate methodology, we also reviewed existing city related scenario projects from literature. In order to avoid a mere technology focus in smart city projects, Eschenauer et al. (2017) examine three methods of scenario development (formative, intuitive, delphi), involving three different stakeholder groups to answer the question, how scenario development can support smart city transformations [21]. As opposed to their approach, we ensured a balanced choice of participants by means of a stakeholder map and recommendations of city representatives. On the other hand, we considered their recommendations to create a catalogue of influence factors and to include a partner with scenario planning experience. Ronay and Egger (2014) examine the role of smart city stakeholders and Near Field Communication technology within tourism industry based smart city 
concepts [22]. The authors use scenario planning to discuss the plausibility of respective future scenarios. The underlying methodology relates to von Reibnitz (1987) and Gausemeier et al. (1996), but the approach is strongly industry-specific, making it hard to be used in a holistic smart city context [10], [23].

In conclusion, we therefore decided to work with the scenario management approach as suggested by Fink/Siebe (2016) based on von Reibnitz (1992) and Gausemeier et al. (1996), which will be outlined in the following section before we cover its specific application and the developed scenarios as part of Action Design Research (ADR) [12], [10], [23].

For a balanced methodological review, also points of criticism regarding the scenario technique need to be addressed. Complexity reduction as an inherent part of the method can be considered ambivalently. On the one hand, it is required to approach a complex topic; on the other hand, important details may be neglected. In this respect, also the low prediction accuracy is criticised. Considering the complex environment of future cities and the fact that the value of scenarios is rather awareness than prediction accuracy, these downsides seem acceptable to a certain degree [24].

A commonly stated point of criticism is the high dependency of results on the participants and their level of expertise, their ability for connected thinking and their willingness for active participation [24]. In the presented case, appropriate expertise was ensured by working with an experienced moderator and by the careful selection of scenario team members. In fact, the city representatives as experts themselves were asked to suggest local experts from a predefined set of domains. The challenging task to ensure active participation was tackled with regular communication but also the online format of workshops made it easier to take part. Further points of criticism are acceptance problems of people who have not taken part in the process and the lack of intuitive instructions for result-based problem solving [25]. To address the acceptance problem, not only target-oriented communication and process transparency but also professional management of expectations is vital. Accordingly, the results need to be presented as a tool to be used in strategic planning, not as a solution itself. Apart from this, the lack of theoretical grounding for the use of scenarios is criticised [26].

Literature confirms the need for a holistic approach to smartness concerning city governance and policy decision making to avoid a mere technological, fast-paced but uncoordinated smart city development. In line with a call for suitable instruments that serve as a compass on the way to a smarter future, Scenario Management is suggested to be used as a strategic tool [27].

\subsection{Scenario Management}

The scenario management process consists of three phases: 1) preparation, 2) development and 3) interpretation of future scenarios. The preparation phase covers formal issues of the project and the organizational setup. Formalities comprise the definition of the subject matter, goals, the definition of the future horizon and the regional scope of the scenario process [12]. Furthermore, it contains the composition of a heterogeneous scenario team, the distribution of roles and the coordination of a collaboration pattern and format. 
The development of scenarios is carried out in three sub-phases, 1) Scenario Field Analysis, 2) Scenario Prognostics, and 3) Scenario Development.

Sub-Phase 1: Scenario Field Analysis. In the Scenario Field Analysis, a set of key factors needs to be identified that describes the scenario field. To reach this goal, four steps have to be followed [12]:

- $\quad$ Step 1: Structuring the scenario field.

- $\quad$ Step 2: Identifying influence factors.

- $\quad$ Step 3: Analyzing the influence factors.

- $\quad$ Step 4: Selecting key factors.

In the first step, the scenario field is structured by subdividing it into system levels (e.g. the general environment, the regional environment, citizens, etc.) and influence areas (e.g. technology, living, work, etc.). The system picture visually summarizes the scenario field and guides the further process (see fig. 2). In the second step, a catalogue is developed to collect and describe influence factors for each of the influence areas. At this point, the number of factors is still unrestricted, and factors can be identified e.g. by surveying the relevant stakeholders, by reviewing literature, or by assessing existing influence factors from similar studies [12]. In the third step, the collected influence factors are then analyzed by assessing their importance, uncertainty and potential influence with the help of a questionnaire (questionnaire 1 ) and/or by examining their relationship with each other in an influence matrix. Visualizations of the influence matrix, like e.g. in a system grid, provide hints for suitable key factors by revealing their influence on each other (see fig. 3, 4) [12]. This allows for the selection of approximately 20 key factors in step four.

Sub-Phase 2: Scenario Prognostics. Scenario Prognostics systematically identifies possible future developments (also known as projections) for each key factor. Therefore, a second questionnaire (questionnaire 2) is used to ask the participants about questions, trends and insecurities regarding every key factor's future. First, two characteristic projections per factor are defined. Second, the derived projections are opposed in a matrix to identify a maximum of five projections per key factor (see fig. 5) [12]. Each key factor is dealt with separately, so that no conclusions can be drawn from this step regarding the coherence of the factors and projections. Furthermore, also explanations and possible implications of the defined projections did not matter at this point [12].

Sub-Phase 3: Scenario Development. In the Scenario Development phase, so-called 'draft scenarios' as a cluster of consistent bundles of future projections are derived. The consistency of the projections is assessed by using a consistency matrix, before a software determines plausible projection bundles. An iterative cluster analysis then groups similar projection bundles to a reasonable number of draft scenarios. The projection bundles are visualized in a 'future map' by means of multidimensional scaling (see Figure 7) [12]. An overview matrix displays all scenarios (columns), key factors (rows) and projections (cells), and serves as a base to formulate the scenarios.

The interpretation includes the communication and the assessment of the developed scenarios, as well as the analysis of their implications. For an effective communication, scenarios need to be verbalized in condensed form considering the language and the interests of the target group. The assessment usually involves a 
questionnaire (questionnaire 3), asking the scenario team members to assess the propinquity of the scenarios to the present, the expected, and the desired future. In a final step, implications in terms of chances and risks are assessed for each scenario [12].

\subsection{Action Design Research Framework}

After reviewing the seven Design Science Research (DSR) guidelines by Hevner et al. [28] and the differentiation between different DSR genres by Peffers [29], we chose ADR as described by Sein et al. [29] as the appropriate research design. The applied research process complies with the four characteristics as outlined by Peffers [29]. Hence, the focus of the paper is to develop a problem-solving artifact in form of future scenarios of cities in South Westphalia, triggered by the difficulties in planning of smart city projects in view of an unknown future and in a setup of 25 participating municipalities. The class of problems addressed is systematic smart city development in today's complex and dynamic world. The participation of stakeholders and end-users in the scenario team ensured learning from intervention by collaboration through questionnaires in parallel to the work of the internal core scenario team. The evolving artifact is ingrained in scenario planning theory, stipulating a sequential development process. Moreover, a continuous evaluation of the artifact was conducted through the inquiry of stakeholders in every phase of the scenario process. The four stages of ADR have been mapped with the described scenario process in fig. 1, serving as the framework for our study.

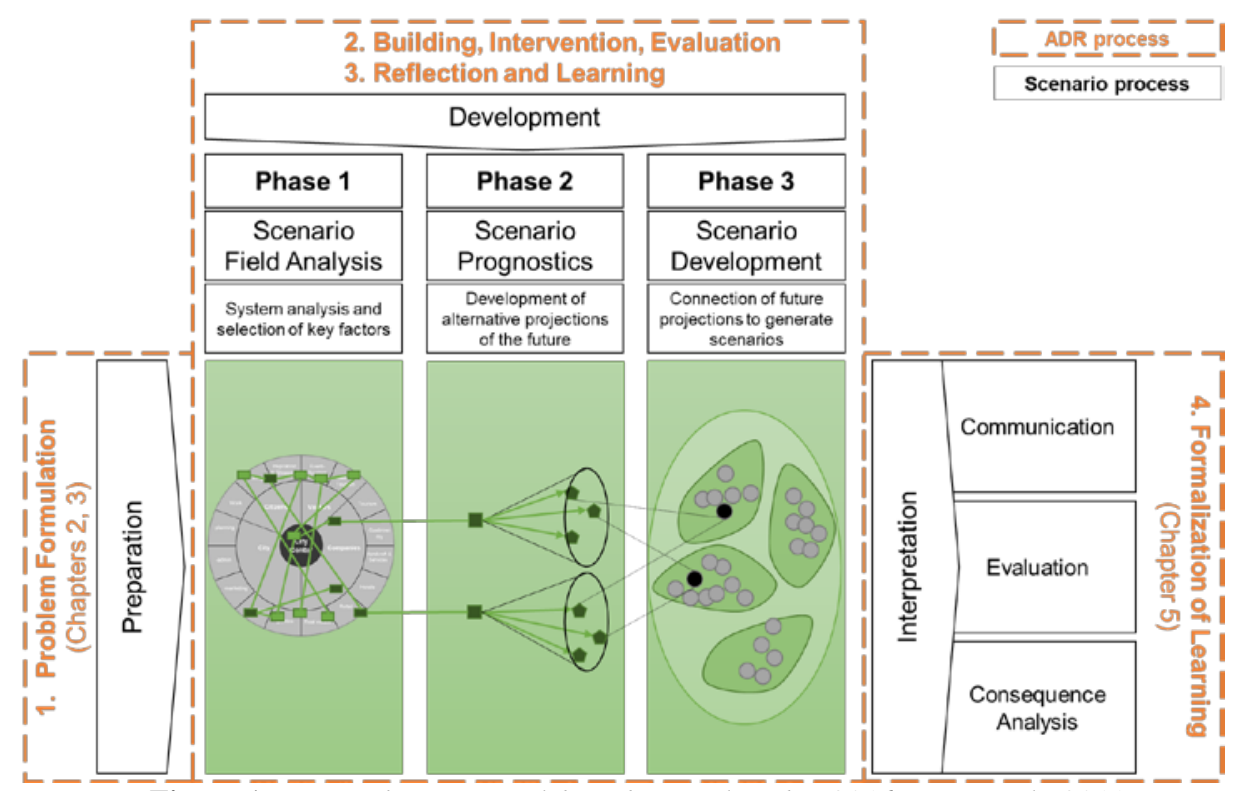

Figure 1: Research Framework based on Fink/Siebe (2016), Sein et al. (2011) 
The core outline of fig. 1 stems from the original work by Fink and Siebe (2016), however, the graphical elements are marginally adapted, translated and integrated into the surrounding ADR process (Sein et al. 2011) with references to the respective chapter of this paper in which the process step is performed. The four ADR stages also represent the respective seven ADR principles and exhibit clear parallels to the scenario process. For instance, principle 3 (reciprocal shaping) is inherent in the iterative scenario development process including workshops and the consideration of feedback in the final scenarios, i.e. the artifact. Furthermore, principle 4 (mutually influential roles) is reflected in the heterogeneity of the team that ensures mutual learning of researcher and practitioners.

\section{South Westphalia City Scenarios 2030}

\subsection{Process Preparation}

The scenario process aims to develop scenarios that describe possible futures of city centers in South Westphalia in 2030. With the help of the developed scenarios, the project team behind the City Lab Südwestfalen, consisting of three academic partners and two chambers of industry and commerce (IHKs), aims to support the participating cities (resp. city stakeholders) in making more robust decisions and to initiate sustainable measures for increasing their city's attractiveness.

The project context guaranteed organizational commitment of the participants. By signing a Letter of Intent, the participating cities manifested their motivation while Scenario Management International (ScMI) AG from Paderborn (Germany) was commissioned as a service provider to moderate the process. Two teams were established: The core scenario team consisted of three members of one of the academic partners and two members of the service provider. The core team was responsible for preparing, moderating and following up on the workshops. The scenario team, consisting of the core team members plus twelve representatives of the participating cities, was involved in the scenario workshops and participated in three questionnaires. The heterogeneity of the team was ensured by systematically requesting participants from different stakeholder fields in all 25 cities as proposed in literature [31-32]. As a result, representatives from retail, services, politics, tourism, startups, architecture and city marketing from nine different cities took part. The use and outline of the three questionnaires was part of the general process of the service providers and has proven as a best practice method to systematically include the participants' feedback. Each questionnaire is designed specifically for the respective process step. While questionnaire 1 was provided as an Excel sheet prepared for the participants input, questionnaires 2 and 3 were dispatched as a PowerPoint file with prepared input fields. The participants had about two weeks' time to send back their feedback which was discussed in the followed workshop.

In the initial project plan two scenario team workshops in person were scheduled, one to cover the first two phases of the scenario process and one to cover the interpretation which reflects stages two until four of ADR (see fig. 1). Due to the COVID-19 restrictions, the format was switched to a complete online setting and a third workshop was added to reduce the required workshop time in order to avoid fatigue. 
Since the participants had to assess factors like health care or gastronomy offerings, questions came up if and how the new situation should be considered in view of the upcoming COVID-19 pandemic. Since, at this time, nobody could foresee the extend, duration and effects of the crisis, the participants were asked to consider the current situation including the pandemic as far as it was assessable at this time.

\subsection{Phase 1 - Scenario Field Analysis}

In order to prepare for the next steps, the core team defined a system picture, as depicted in fig. 2. It consists of seven different system levels including 21 influence areas in total. The groundwork for the system picture was developed during a kick-off meeting of the City Lab Südwestfalen together with 46 city representatives. In a world café setup, typical roles of city centers and important factors that have turned cities into what they are today were discussed, providing a starting point to identify the system levels and influence areas.

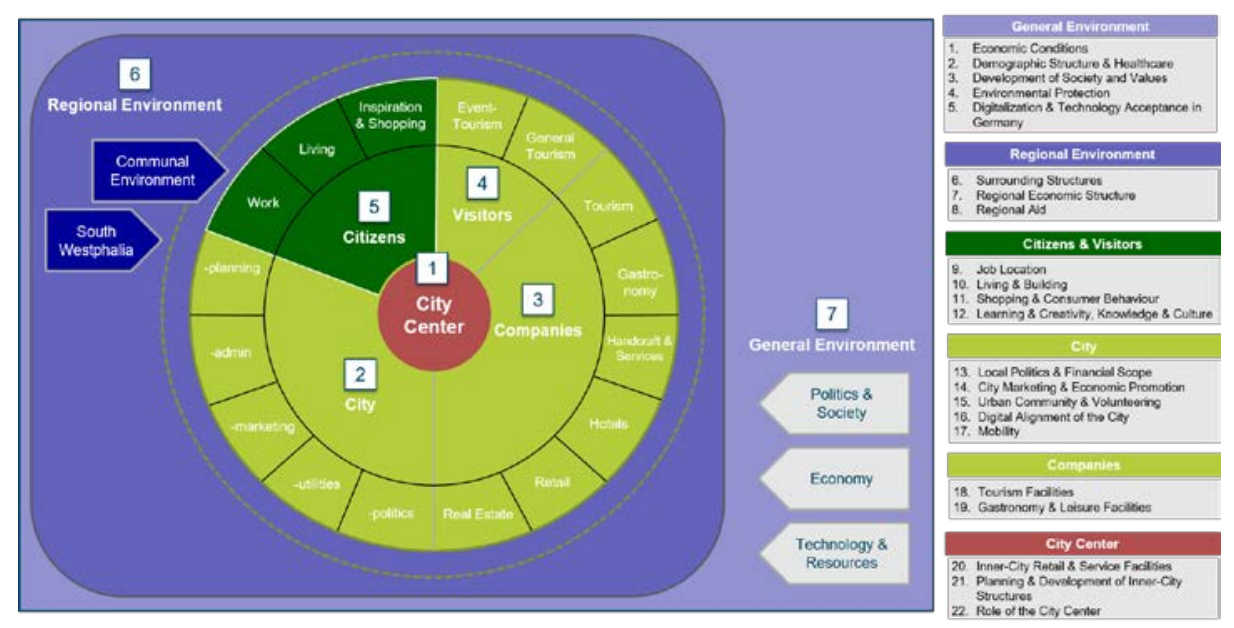

Figure 2: System Picture and Key Influence Factors

Based on the system picture, 63 influence factors have been identified by the core team. This set of influence factors was suggested to the scenario team by sending out a questionnaire, asking for feedback and missing factors. The scenario team members were asked to evaluate every single influence factor on a 5-point Likert scale regarding its:

- Importance: How important is this factor for the development of city centers in South Westphalia?

- Uncertainty: How predictable is the future development of this factor?

- Designability: To what degree can the future development of this factor be influenced by city stakeholders? 
In total, questionnaire 1 was dispatched to 71 respondents in 24 different partner cities. We received back 25 questionnaires from 16 cities, resulting in a response rate of $17.75 \%$.

At the same time, the members of the core team created the influence matrix depicted in fig. 3. In this matrix, the impact that the 63 influence factors have on each other is assessed by rating it using a scale from 0 (no impact) to 3 (strong and direct impact) [12].

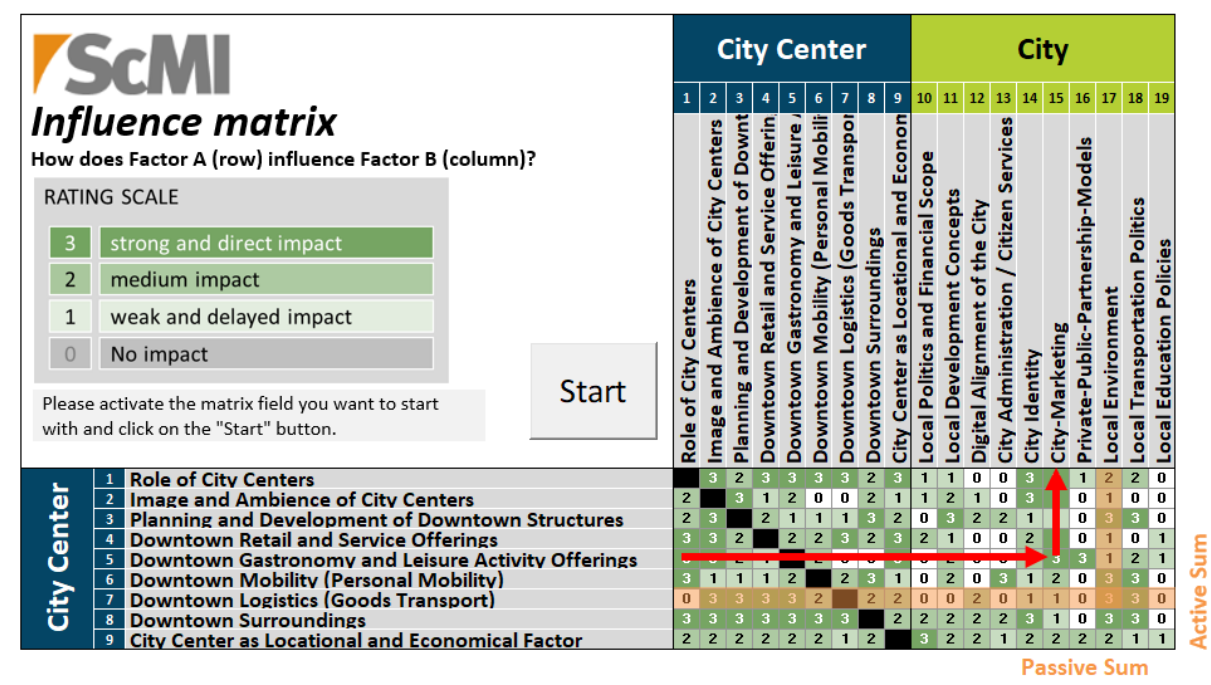

Figure 3: Excerpt of the Influence Matrix

Three parameters can be derived from these ratings: 1 ) the active sum as the overall strength of the impact that a given factor has on the other factors; 2) the passive sum as the overall strength of the impact that the other factors have on a given factor; 3) a dynamic index as the degree of inclusion of a given factor in the entire system [12].

In a system grid, these parameters can be visualized in order to recognize the dynamics and dependencies between the different factors [12]. Fig. 4 shows the system grid as a result of the influence matrix. The activity of a factor is applied on the y-axis, whereas the passivity is applied on the x-axis. Four different areas are distinguished: leverage factors with a wide influence on the whole system (upper left corner), system knots with a high connectivity with other factors (upper right corner), system indicators that are strongly influenced by other factors (bottom right corner), and independent factors with a low influence on the system (bottom left corner) [12].

These two steps, the influence matrix and the scenario team questionnaire 1 , were used to identify the key factors that could be considered in the further process while keeping the scenario process manageable [12]. 
Once the suggested key factors were identified by the core team, they were extensively discussed in a first (online) scenario workshop with all members from the scenario team, leading to a final set of 22 key factors to proceed with (see fig. 2). This step represented the alpha cycle of the ADR approach with an evaluation of the key factors to refine them as a first outcome of the artifact [30].

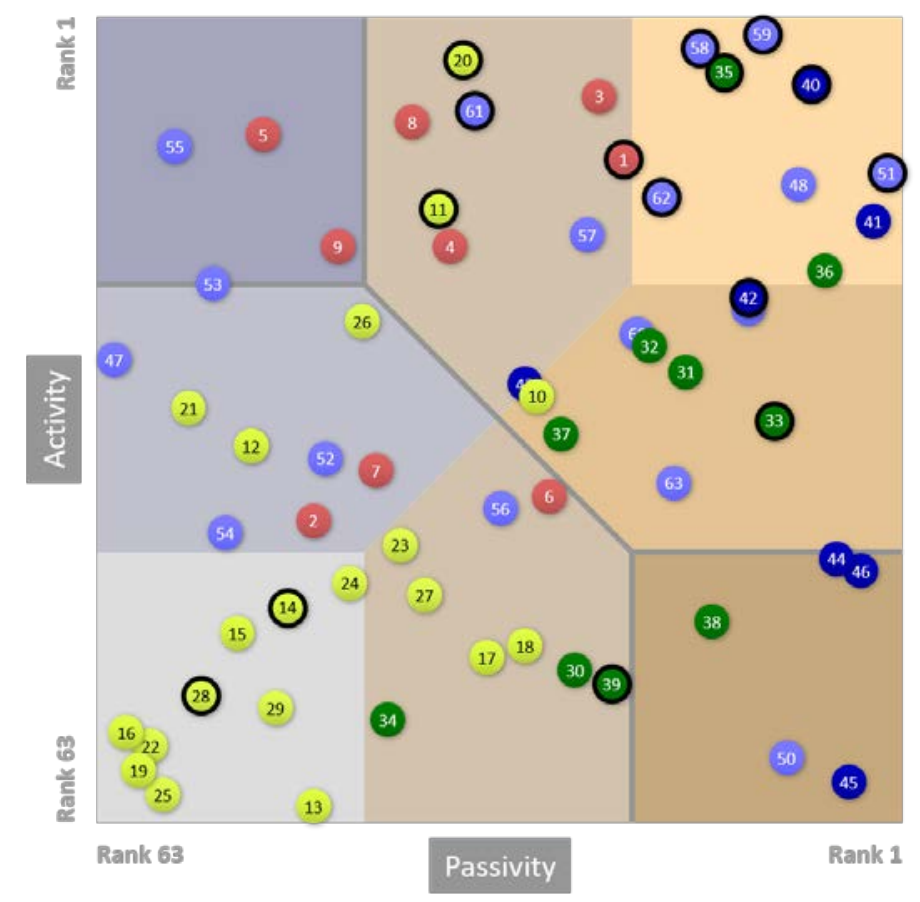

Figure 4: System Grid

\subsection{Phase 2 - Scenario Prognostics}

Within this process step, alternative projections for all key factors were generated, in order to prepare for the scenarios as internally consistent projection bundles [12]. The process step started with questionnaire 2, addressing the scenario team. The scenario team members were asked to report all questions that came to their mind regarding each key factor's future development. Based on these questions, the core team developed the different future projections. During a second workshop with the scenario team, the projections for all key factors were presented and discussed, leading to 108 projections for the 22 key factors. As an example, fig. 5 shows the projections for the key factor "Role of the City Center". This factor draws on the function the city center fulfils and regards it either as a place to go for shopping 
(marketplace) or as a place to visit as a pastime, like a theme park (world of experience).

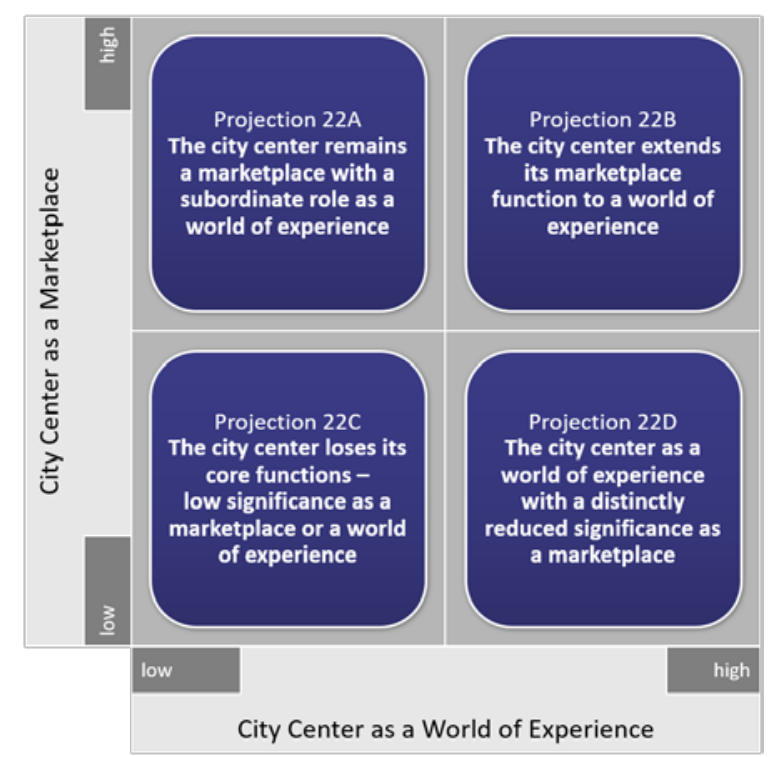

Figure 5: Scenario prognostics of the key factor 'role of the city center'

In the next step, not only the scenario team members, but also a set of further city representatives that had been involved in the City Lab Südwestfalen before, were approached with questionnaire 3 to evaluate the projections from their individual city's perspective. Later, after the scenarios had been compiled, these evaluations allowed the core team to provide individual feedback to the cities regarding what scenario (as a consistent set of projections) is most similar to the current situation of each city, and what scenarios are the most expected and the most favored ones. For this, the respondents rated each projection regarding its match with the presence, its likelihood, and its desirability on a Likert scale from 1 (lowest) to 5 (highest). Questionnaire 3 was dispatched to 38 participants from 24 partner cities and resulted in a response rate of $71 \%$ (27 responses).

The developed projections for the set of key factors reflect the beta evaluation cycle described in the ADR research framework [30].

\subsection{Phase 3 - Scenario Development}

After agreeing on the projections and after collecting the evaluations from the extended scenario team, the scenarios were compiled with the help of a software-driven consistency analysis [12]. Using ScMI's scenario software, the projections were set into relation with each other by assessing their plausibility [12]. Especially when dealing with a high number of factors and projections, the software, being a proprietary development of ScMI, is a useful tool to ensure reliable results and save time. This 
software-supported approach led to a set of eight draft scenarios, which were visualized by means of multidimensional scaling in a so-called 'future space mapping' ${ }^{1}$ (fig. 7). In this mapping, four core dimensions could be identified, which fundamentally differentiate the scenarios: (A) Economic development and digitization, (B) Quality of life and participation, (C) Sustainability and regionality and (D) Retail and marketplace function. This tool-based process was followed by a core team discussion, in which the scenarios were selected and a first draft of the 'map of the future' was derived.

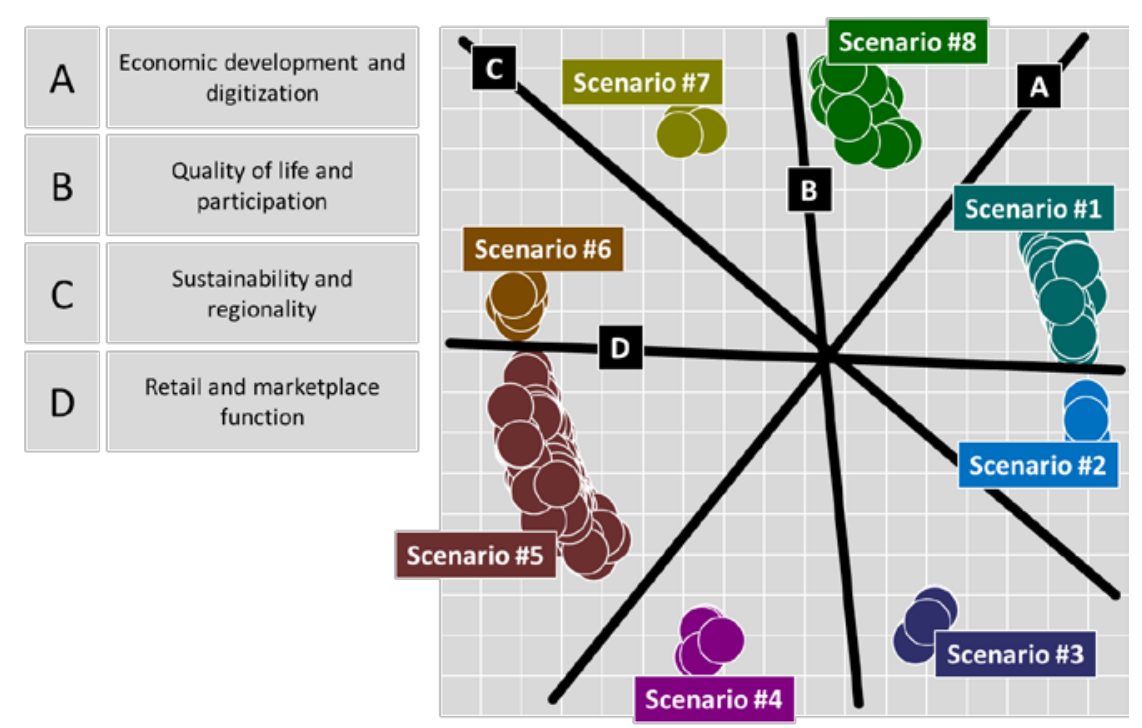

Figure 6: Draft Scenarios and core dimensions in a multi-dimensional scaling

\section{$5 \quad$ Interpretation of Results}

\subsection{Scenario Communication}

The scenario development process resulted in the eight draft scenarios depicted in fig. 6. This rather technical visualization was then schematized and transformed into a simpler form of a 'map of the future' (fig. 7). Each of the scenarios was verbalized in a story, covering its most characterizing projections. In the following, each scenario is outlined in brief, before one scenario is described in more detail.

Scenario \#1 ('Regional Marketplace') describes a promising future where the city center has turned into a magnet for local shoppers and tourists. Scenario \#2 ('Experience Instead of Shopping') pictures a city center that has developed from a marketplace into an entertainment area, mostly because of digitalization and a changed buying behaviors. As a result of social distancing and service orientation, Scenario \#3 ('Service Shapes Reinvention') outlines a city center with displaced retailers, which

1 For details on future space mapping, see [12], p. 111ff. 
is mainly visited for services. Presenting the first outlook to a rather negative future, scenario \#4 ('Abandonment of the City') sketches a web-focused smart city, which is attractive online, but mostly neglected in physical life. While in scenario \#5 ('Desertification of the City'), the city center loses any of its functions with today's players having disappeared, in scenario \#6 ('Chains Shape the Shopping City'), the importance of the marketplace function remains. However, in this scenario chain stores prevail over local owner operated retail outlets. Scenario \#7 ('Back to the old City') describes the city center in its traditional form, in which the smart city concept did not have any profound impact. Eventually, scenario \#8 ('City Center as an Anchor') tells the story of a city center that has developed into the focal point of social life, with a flourishing gastronomy and distinct citizen participation.

Regarding the future role of the city center, the outlined scenarios can be grouped into four clusters: In scenarios \#1 and \#8, city centers extent their marketplace function by providing experience opportunities. In scenario \#2 instead, the experience-factor takes the dominant role and high street shopping loses importance. Scenarios \#3 to \#5 pose a threat to current city businesses, since the city center loses its current core functions and either focuses on service provision (\#3) or entirely loses its allure (\#5). Finally, the fourth cluster depicts city centers that predominantly serve as marketplaces (\#6 / \#7).

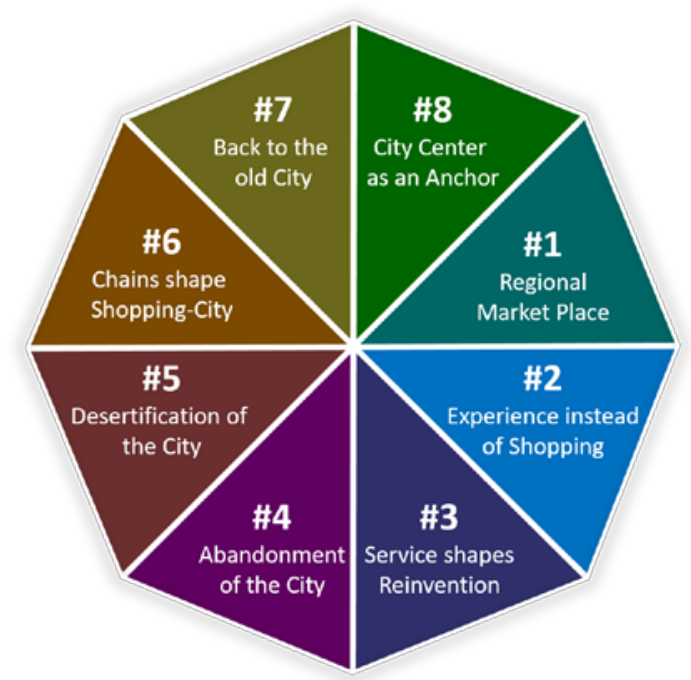

Figure 7: Map of the future for city centers in South Westphalia until 2030

As an example, the story of scenario \#4 is provided in the following: The prospering economy supports a digital Germany with innovation grants for cities. Digitalization has made the society more independent and has led to less physical contacts. As opposed to the far-reaching digital advancements, the physical infrastructures and existing businesses are neglected. Unsatisfactory local facilities for healthcare, education and work make it hard for the city to provide a high quality of life in its city 
center. To reduce the need for commuting, the city tries to attract new businesses by highlighting its digital image with the support of city marketing promoting its online facilities. Unfortunately, the city missed out on integrating the physical city center into its smart city concept. Despite sufficient financial means, political activities regarding the city center are rather passive. Citizens have lost their identification with the city center and turned into online shoppers. Without incentives and reasons to visit, citizens rarely go downtown and gastronomes lose ground. In this dark scenario, the city fails to clearly position itself either as a marketplace, as a world of experience, or as both. It forfeits its attractiveness in a self-reinforcing downward spiral.

\subsection{Scenario Assessment}

After the scenarios have been finalized, the individual evaluations of the projections from Phase 2 allowed the core team to analyze 1) which scenario matches the current situation in each city best, 2) which scenario the city expects, and 3) which scenario it favors. It turned out that most cities hope for scenarios \#1, 2 or 8 . At the same time, the majority of the participating cities also expect one of these scenarios to become true. As compared to the current situation, scenario \#8 was rated the most fitting. While these overall results might leave the impression of strong starting points and optimistic perspectives, it needs to be pointed out that these evaluations are nothing more than subjective appraisals and that several of the cities also show different results. It is important to mention, that the scenarios need to be considered as strategic tools to work with and not as reliable guidelines.

The scenarios and the evaluations have been communicated on the final online workshop not only to the scenario team but also to further representatives of the participating cities. After all scenarios had been presented in brief, the audience was split into five online meeting rooms in order to discuss appropriate measures in accordance with the characteristics and the implications of one specific scenario. Following these split-sessions, the ideas were presented to the entire audience again, in order to point out how the scenarios could be utilized in decision-making and in strategic planning.

As a final step and following up on the completed process, a report will now be created with a detailed documentation of the scenario project, the developed scenarios and the city-specific evaluations.

\section{Conclusion}

The EFRE-project City Lab Südwestfalen aims to strengthen the attractiveness of city centers in rural areas like South Westphalia. For this, it is highly important to ascertain the challenges and uncertainties that the cities are faced with today and in the future. In such complex and uncertain situations, scenario management can facilitate more robust decision-making, better strategic alignment, smarter investments, futureoriented thinking, and also attentive monitoring [11]. 
This paper describes a complete scenario process that was accomplished between 02.2020 and 07.2020 to address the two research questions of how city centers in South Westphalia can prepare themselves for an unknown future (RQ 1) and how they could look like in 2030 (RQ 2). For this purpose, a combination of ADR and scenario management was used as a framework to develop scenarios in a multi-stakeholder process. A better understanding of needs and problems that city stakeholders in rural areas are faced with could be obtained through the collaboration with diverse city stakeholders in a heterogeneous scenario team.

Through this structured and participatory process, eight scenarios were developed, which, first of all, describe possible future developments of cities in South Westphalia. In principle, the results can be transferred to other regions with similar conditions. These scenarios point out the different developments and roles that cities might take in the future, answering RQ 2. The overall scenario process that we ended up with and that lead the way to the derived scenarios answers RQ 1.

The scenarios that have been worked out gain a special value because they can be evaluated separately for individual cities. In this way, individual needs and wishes for change can be identified. In addition, a repeated evaluation makes it possible to monitor current and future perspectives.

With regard to the COVID-19 pandemic which came up at the very beginning of the process, initially it was unclear how well the process will work in a purely online format, since situational factors of participation, engagement and group dynamics play an essential role in the workshops. Although incomparable to a physical workshop, many intensive discussions came up and no technical issues hampered the process. Moreover, the online workshops caused less organizational effort for both the participants and the moderators. An examination of differences between the online and offline format in the process flow and results leave room for future research. As intended, the COVID-19 pandemic had an influence on the results, e.g. to be noted in the inclusion of 'social distancing' in scenario \#3.

Future research should also assess if and in what way the scenario process and the developed scenarios have been and could be embedded in future-robust decisionmaking and strategic planning in the participating cities.

\section{References}

1. United Nations Department for Economic and Social Affairs: World Urbanization Prospects 2018. Highlights (ST/ESA/SER.A/421). United Nations, New York (2019)

2. Ministerium für Wirtschaft, Innovation, Digitalisierung und Energie des Landes Nordrhein-Westfalen: Handelsszenarien Nordrhein-Westfalen 2030 (2019)

3. ISO/IEC JTC1: Smart cities - Preliminary report. Information Technology (2015)

4. Caragliu, A., del Bo, C., Nijkamp, P.: Smart Cities in Europe. Journal of Urban Technology 18 (2009) 
5. Giffinger, R., Fertner, C., Kalasek, R., Pichler-Milanovic, N.: Smart cities Ranking of European medium-sized cities. Vienna University of Technology (2007)

6. Gassmann, O., Böhm, J., Palmié, M.: Smart cities. Introducing Digital Innovation to Cities. Emerald Publishing Limited, Bingley, UK (2019)

7. ZDFheute: Städtetag warnt vor Innenstadt-Sterben, https://www.zdf.de/nachrichten/wirtschaft/coronavirus-innenstaedte-102.html (Accessed 23.7.2020)

8. Bundesministerium des Innern, für Bau und Heimat: Neuer Zuschuss für Stadtentwicklung und Digitalisierung: Modellprojekte Smart Cities, https://www.bmi.bund.de/SharedDocs/pressemitteilungen/DE/2019/04/smartcities-modellprojekte.html (Accessed 14.7.2020)

9. Hornbostel, L., Nerger, M., Tillack, D., Wittpahl, V., Handschuh, A., Salden,s J.: Zukunftsradar Digitale Kommune. Ergebnisbericht zur Umfrage 2019 (2019)

10. Reibnitz, U.: Szenario-Technik. Instrumente für die unternehmerische und persönliche Erfolgsplanung. Gabler Verlag, Wiesbaden (1992)

11. Mietzner, D.: Strategische Vorausschau und Szenarioanalysen. Methodenevaluation und neue Ansätze. Gabler Verlag / GWV Fachverlage GmbH Wiesbaden, Wiesbaden (2009)

12. Fink, A., Siebe, A.: Szenario-Management. Von strategischem Vorausdenken zu zukunftsrobusten Entscheidungen. Campus Verlag, Frankfurt, New York (2016)

13. Burmeister, K.G., Neef, A., Beyers, B.: Corporate Foresight. Unternehmen gestalten Zukunft. Murmann, Hamburg (2004)

14. Godet, M.: Creating futures. Scenario planning as a strategic management tool. Economica, London (2001)

15. Gordon, T.J.: Trend Impact Analysis. AC/UNU Millennium Project. Futures Research Methodology (1994)

16. Schwartz, P.: The Art of the Long View. Paths to strategic insight for yourself and your company. Bantam Doubleday Dell Pub. Group, New York (1996)

17. van der Heijden, K., Bradfield, R., Burt, G., Cairns, G., Wright, G.: The Sixth Sense. Accelerating Organizational Learning with Scenarios. John Wiley \& Sons Ltd, Hoboken (2002)

18. Schoemaker, P.: Profiting from uncertainty. Strategies for succeeding no matter what the future brings. Atria Books, New York (2002)

19. Ramirez, R., Wilkinson, A.: Strategic Reframing. The Oxford Scenario Planning Approach. Oxford University Press, Oxford (2016)

20. Cairns, G., Wright, G.: Scenario Thinking. Preparing your organization for the future in an unpredictable world. $2^{\text {nd }}$ edit., Palgrave/Macmillan, Basingstoke (2018)

21. Eschenauer, U., Braunreiter, Lukas, Kühn, Tobias, Yildirim, O., Lobsiger-Kägi, E., Spiess, H., Carabias, V., müller, A.: Smart City in Theorie und Praxis. Szenarien, Strategien und Umsetzungsbeispiele (2017)

22. Ronay, E., Egger, R.: NFC Smart City: Cities of the Future A Scenario Technique Application (2014) 
23. Gausemeier, J., Fink, A., Schlake, O.: Szenario-Management: Planen und Führen mit Szenarien. 2nd edit., Hanser, München (1996)

24. Schönauer, D.: Nutzen der Szenario-Technik für die Personalentwicklung bei Mercedes-Benz. Diplomica Verlag, Norderstedt (1999)

25. Dönitz, E.: Effizientere Szenariotechnik durch teilautomatisiche Generierung von Konsistenzmatrizen. Gabler, Wiesbaden (2008)

26. Neuhaus, C.: Zukunft im Management. Orientierung für das Management von Ungewissheit in strategischen Prozessen. Carl-Auer-Verlag, Heidelberg (2006)

27. Castelnovo, W.; Misuraca, G.; Savoldelli, A.: Smart Cities Governance: The Need for a Holistic Approach to Assessing Urban Participatory Policy Making. Social Science Computer Review 34(6), 724-739 (2016)

28. Hevner, A. R., March S. T., Park J., Ram, S.: Design Science in Information Systems Research. MIS Quarterly 28, 75-105 (2004)

29. Peffers, K., Tuunanen, T., Niehaves, B.: Design Science Research Genres: Introduction to the special issue on exemplars and criteria for applicable design science research. European Journal of Information Systems 27, 129-139 (2018)

30. Sein, M. K., Henfridsson, O., Purao, S., Rossi, M., Lindgren, R.: Action Design Research. MIS Quarterly 35, 1-20 (2011)

31. Gassmann, O., Böhm, J., Palmié, M.: Smart City. Innovationen für die vernetzte Stadt - Geschäftsmodelle und Management. Hanser, München (2018)

32. Schlake, O.: Verfahren zur kooperativen Szenario-Erstellung in Industrieunternehmen. HNI-Verlagsschriftenreihe, Band 67, Paderborn (2000) 